\title{
Editorial: Coasts Under Changing Climate: Observations and Modeling
}

\author{
Rafael Almar ${ }^{1 *}$, Marta Marcos ${ }^{2}$, Gonéri Le Cozannet $^{3}$ and Roshanka Ranasinghe ${ }^{4}$ \\ ${ }^{1}$ LEGOS/IRD, Toulouse, France, ${ }^{2}$ Department of Physics, University of the Balearic Islands, Palma de Mallorca, Spain, \\ ${ }^{3}$ Bureau de Recherches Géologiques et Minières, Orléans, France, ${ }^{4}$ International Institute for Infrastructural Hydraulic and \\ Environmental Engineering (IHE Delft) Institute for Water Education, Delft, Netherlands
}

Keywords: numerical modeling, earth satellite observations, artificial intelligence, data-driven models, forecast, remote sensing-GIS

\section{Editorial on the Research Topic}

\section{Coasts Under Changing Climate: Observations and Modeling}

As sea-level rises due to climate change, providing salient information to support coastal risk management and adaptation is becoming a critical issue for numerous coastal communities and economic activities. The way this information is produced is now evolving rapidly as new observation and modeling capabilities are becoming available. This includes numerous multiscale, multi-platform, terrestrial, airborne, and spatial remote sensing data, which can be combined with numerical modeling tools to improve our capabilities to reproduce past coastal evolutions and disasters, as well as to anticipate the future (e.g., Copernicus satellite and climate services). This Research Topic presents new research supporting coastal engineering and risk management, land use planning, integrated coastal zone management and coastal adaptation. It includes studies using and combining observations (e.g., in-situ, aerial, remote sensing) and models to understand and anticipate future coastal risks. Observation and modeling are key to facilitate the design and

OPEN ACCESS

Edited and reviewed by:

Charitha Bandula Pattiaratchi,

University of Western

Australia, Australia

*Correspondence:

Rafael Almar

rafael.almar@ird.fr

Specialty section: This article was submitted to Coastal Ocean Processes, a section of the journal

Frontiers in Marine Science

Received: 29 September 2021

Accepted: 12 October 2021

Published: 01 November 2021

Citation:

Almar R, Marcos M, Le Cozannet G and Ranasinghe $R$ (2021) Editorial:

Coasts Under Changing Climate:

Observations and Modeling.

Front. Mar. Sci. 8:785608.

doi: 10.3389/fmars.2021.785608 implementing prevention solutions that mitigate coastal risks. Among the articles published in this Research Topic, most deal with deterministic or probabilistic modeling with observations used for model validation and initialization. Six articles address coastal flooding, three address coastal erosion and one article focuses on ecosystem damage, while two articles concern coastal policy and management.

Flooding is often a result of the compound processes acting at multiple space scales, such as wind, waves, and surges, and their impacts on coastal zones is generally most accurate at local scales, where the flooding dynamics can be best represented. The contribution in this Research Topic, Höffken et al. investigates the influence of the duration and intensity of storm surge events on flood extent and water depths in coastal zones, and assesses the associated flood exposure for the case of the municipality of Eckernförde, Germany. Another local study by Orejarena-Rondón et al. presents an analysis on the coastal flooding impacts of the combined effect of extreme waves and sea level extremes in Bocagrande, Cartagena (Colombia). Both studies also evaluate the impacts of projected mean sea-level rise, further demonstrating the. Trošelj et al. quantify the impact of two extreme storm surge events in October 2006 on the Ibaraki Coast (Japan) in terms of sea surface elevation, water velocities and hydrographic imprints, using a fine $(2 \mathrm{~km})$ resolution dynamical downscaling.

Other studies in this Research Topic build upon the recent progresses obtained in broad scale or global flood modeling by the coastal scientific community. Tadesse et al. explore the potential of data-driven models to simulate storm surges based on atmospheric fields and indices at global scale. They find that at $\sim 70 \%$ of tide gages, mean sea-level pressure is the most important predictor to model daily maximum surge. Instead of using a statistical approach, Muis et al. present a novel CMIP6 global dataset of extreme sea levels, the Coastal Dataset for the Evaluation of Climate Impact 
(CoDEC), generated with a hydrodynamic model, which can be used to accurately map the impact of climate change on coastal regions around the world.

Understanding the long-term (50-100 year) evolution of coasts perturbed by human activities in a changing climate is of great importance for coastal zone planners and managers. Roelvink et al. present a new free-form coastline model, ShorelineS, that is able to simulate long term, local scale shoreline change based on relatively simple principles of alongshore transport gradient driven changes as a result of coastline curvature, including under highly obliquely incident waves. The model can reproduce complex behavior such as a splitting and merging of coastlines, and longshore transport disturbance by hard structures. Also describing possible evolution of coastal systems, the contribution by Bamunawala et al. focuses on the development and piloting of an innovative reduced complexity model G-SMIC that can probabilistically simulate climatechange driven evolution of inlet-interrupted coasts at 50-100 year time scales, while taking into account the contributions from catchment-estuary-coastal systems in a holistic manner. GSMIC also quantifies the input-driven uncertainties associated with the evolution of Catchment-Estuary-Coastal systems over the twenty-first century.

A global increase in coastal hypoxia has emerged over the past decades due largely to a considerable rise in anthropogenicallyderived nutrient loading. Zhou et al. investigate the physical and biogeochemical processes that create high-biomass phytoplankton production and hypoxia off the Changjiang (Yangtze River) Estuary in the East China Sea. Extensive in situ datasets are linked with a coupled Regional Ocean Modeling Systems (ROMS) and the Carbon, Silicate, and Nitrogen Ecosystem (CoSiNE) model to investigate the temporal decoupling of phytoplankton production and hypoxia. Such studies ultimately support better forecasts and projections of coastal hypoxia.

Finally, some of these multiple vulnerabilities are integrated in the perspective of management and policies. Terorotua et al. emphasize their major role in the co-design of tailored coastal

\section{REFERENCES}

Dada, O., Almar, R., Morand, P., and Ménard, F. (2021). Towards West African coastal social-ecosystems sustainability: interdisciplinary approaches. Ocean Coastal Manage. 211:105746. doi: 10.1016/j.ocecoaman.2021.10 5746

Koroglu, A., Ranasinghe, R., Jiménez, J. A., and Dastgheib, A. (2019). Comparison of coastal vulnerability index applications for Barcelona Province. Ocean Coastal Manage. 178:104799. doi: 10.1016/j.ocecoaman.2019.0 5.001

Conflict of Interest: The authors declare that the research was conducted in the absence of any commercial or financial relationships that could be construed as a potential conflict of interest. climate services based on a case study of French Polynesia. In their contribution, the authors assess climate change perceptions by public authorities and identify their needs with regard to climate-related science. To enable a better anticipation of future risks due to sea level rise, Dayan et al. provide global to regional High-End Scenarios exploring an unlikely, but not impossible, scenario of rapid melting of ice-sheets from now to 2,200, supported by expert elicitation. While Dayan et al. remind that high-end scenarios can be relevant for risk-averse stakeholders concerned with e.g., critical infrastructure, the paper by Terorotua et al. delivers empirical evidence that the governance able to address the challenge still needs to be built up in many regions. Building this adaptation governance and capacity is part of today's coastal adaptation challenge that comes in addition to mitigating climate change and curbing marine and coastal biodiversity losses.

The coastal system can be regarded as co-evolving socioeconomic and ecological systems experiencing substantial environmental pressures owing to the mechanisms of change exerted by human activities against a background of natural and climatic changes (Dada et al., 2021). Planning for the future use of the goods and services available from coastal ecosystems will therefore continue to be influenced or disturbed by unpredictable events. One way to account for the large volume of model projections and observations is their integration into increasingly complex holistic approaches and dissemination to the widest possible audience through simplified indices (Koroglu et al., 2019) available to coastal communities, which will maximize their use in sustainable coastal development and management. Papers in this Research Topic adds evidence for this sustainability challenge being increasingly considered in coastal science and operational coastal zones management.

\section{AUTHOR CONTRIBUTIONS}

RA, MM, GL, and RR contributed to the ideas development and writing. All authors contributed to the article and approved the submitted version.
Publisher's Note: All claims expressed in this article are solely those of the authors and do not necessarily represent those of their affiliated organizations, or those of the publisher, the editors and the reviewers. Any product that may be evaluated in this article, or claim that may be made by its manufacturer, is not guaranteed or endorsed by the publisher.

Copyright (C) 2021 Almar, Marcos, Le Cozannet and Ranasinghe. This is an openaccess article distributed under the terms of the Creative Commons Attribution License (CC BY). The use, distribution or reproduction in other forums is permitted, provided the original author(s) and the copyright owner(s) are credited and that the original publication in this journal is cited, in accordance with accepted academic practice. No use, distribution or reproduction is permitted which does not comply with these terms. 